Revista Aspas

ppgac - USP

Desenhos de Pesquisa

\title{
RESILIÊNCIA E SUSTENTABILIDADE: DESAFIOS DO FAZER TEATRAL DE GRUPOS DE TEATRO DO INTERIOR DE SÃO PAULO
}

\author{
RESILIENCE AND SUSTAINABILITY: CHALLENGES IN MAKING \\ THEATER FOR DRAMA GROUPS IN THE INTERIOR OF SÃO PAULO
} RESILIENCIA Y SUSTENTABILIDAD: DESAFIOS DE LA PRÁCTICA
TEATRAL EN GRUPOS DE TEATRO DEL INTERIOR DE SÃO PAULO

\section{Giovanna Pereira de Souza e Maria Alice Possani}

Giovanna Pereira de Souza

Universidade Sagrado Coração; Formada no curso de Pós Graduação de Especialização em Produção Cultural em Artes

Cênicas: Performance, Teatro, Dança e Circo; Pesquisa concluída, 2019. Área de estudo Produção Cultural em Artes Cênicas. Orientada pela Profa Dra Maria Alice Possani (Unicamp)

E-mail: giovanna.psouza@yahoo.com

Maria Alice Possani

Maria Alice Possani realizou o trabalho de orientação do presente artigo; Doutora em Artes da Cena pela Universidade

Estadual de Campinas (UNICAMP). É uma das fundadoras do

Matula Teatro, coletivo sediado há mais de doze anos em Campinas/SP. Docente no Curso de Graduação em Artes Cênicas da UNICAMP, com atuação nas áreas de Produção Teatral, Direção, Interpretação e Teatro e Comunidade. 


\section{Resumo}

Este estudo teve como objetivo discutir os fatores que cercam os desafios do fazer teatral para grupos de teatro no interior de São Paulo, no que se refere à sustentabilidade e resiliência. A metodologia utilizada foi a realização de entrevistas semiestruturadas de grupos com sede em municípios do interior paulista, de maneira a contemplar diferentes regiões do estado. O trabalho buscou provocar uma reflexão que ampliasse os olhares para a pesquisa no campo das artes cênicas e demonstrar dados que ilustram conjecturas dos fatores em comum e diferenciais nos sujeitos desta pesquisa, quanto à resiliência e sustentabilidade, em manterem-se organizados como um grupo de teatro.

Palavras-chave: Teatro de grupo, Sustentabilidade, Resiliência

\section{Abstract}

The objective of this study was to discuss the factors regarding sustainability and resilience that surround the challenges facing drama groups in the interior of São Paulo. The method used consisted of semi-structured interviews with groups based in municipalities of the state of São Paulo, so that different regions of the state were included. This work aimed at fostering reflection toward broadening the view of research in the field of the performing arts, and at reporting data that illustrate conjectures about the common factors and differences presented by the study subjects regarding, resilience and sustainability, in maintaining the group structured as a drama group.

Keywords: Drama group, Sustainability, Resilience

\section{Resumen}

La presente investigación tuvo como objetivo discutir los factores relacionados a los desafíos de la práctica teatral para grupos de teatro del interior de São Paulo, en lo que se refiere a la sustentabilidad y resiliencia. La metodología utilizada fue la realización de entrevistas semiestructuradas con grupos ubicados en municipios pertenecientes al interior paulista, de manera a abarcar distintas regiones del estado. El estudio buscó provocar una reflexión que pudiera ampliar la mirada para la investigación relacionada a las artes escénicas y demostrar datos que ilustren conjeturas de los factores en común y diferenciales en los sujetos de esta investigación, relativo a la resiliencia y sustentabilidad, en mantenerse organizados como un grupo de teatro.

Palabras Clave: Teatro en grupo, Sustentabilidad, Resiliencia. 


\section{Teatro de grupo e suas particularidades}

${ }^{1} \mathrm{O}$ interesse em realizar esta pesquisa tem origem em minha primeira experiência com teatro de grupo, propiciada pela Quadrilha de Teatro Notívagos Burlescos ${ }^{2}$, através de uma oficina de iniciação teatral. Atividades como essa desempenham um papel fundamental na propagação do conhecimento sobre o teatro, uma vez que as oficinas ofertadas pela Companhia tinham preços acessíveis, tornando-se essenciais para ampliar o acesso às mesmas.

As experiências vivenciadas junta à esse grupo seguem reverberando até hoje, e foram significativas para o desejo de aprofundar o conhecimento/entendimento sobre esse universo através de um olhar científico-acadêmico.

Prerrogativa que culminou na determinação dos objetivos deste estudo, são eles: delinear caminhos para entender quais os fatores que influenciam os grupos de teatro do interior paulista para manterem-se resilientes, como esses grupos se organizam em relação à estratégias de sustentabilidade econômica e quais os desafios encontrados na tarefa de se conservarem em atividade.

O termo teatro de grupo tem raiz no movimento teatral independente. Podemos definir teatro de grupo como manifestações teatrais resultantes de treinamento do ator, do interesse na preservação de elenco, por um projeto de longo prazo e na promoção de atividades pedagógicas (CARREIRA, 2005). Corroborando com essa definição, a pesquisa foi desenvolvida com grupos de teatro que apresentam como característica a construção de trabalhos de maneira coletiva. É comum que, nessas organizações, os atores e membros do grupo criem uma forma própria de conduzir seus trabalhos, implementando uma linguagem que dialoga com as ideias e ideais que procuram ofertar como grupo. Associado a esse processo de criação de identidade, o teatro de grupo

\footnotetext{
'As citações em primeira pessoa se referem as experiências da autora Giovanna Pereira de Souza. ${ }^{2} \mathrm{O}$ grupo Quadrilha de Teatro Notívagos Burlescos tem sede no município de Botucatu/SP e foi fundado no ano de 2002.
} 
vem envolto à uma perspectiva filosófica e torna-se parte integrante da sociedade e de todos os componentes políticos e sociais nela presente.

\section{A busca pelos grupos}

Há uma diferença estrutural e organizacional na dinâmica que envolve os grupos de teatro da capital e dos munícipios do interior paulista, especialmente com relação aos aspectos socioeconômicos.

Vianna (2007), expõe dois cenários, o da capital e o do interior do Estado de São Paulo. No primeiro, o teatro de grupo se fortalece ao multiplicar seus territórios e campo de ação, e muitos grupos formados nas décadas de 1980, 1990 e início do século 21 permanecem atuantes artisticamente e em luta política para que o poder público e sociedade reconheça as especificidades de suas produções artísticas e modos de trabalho, que operam de maneira diferente dos mecanismos da indústria e do mercado cultural. Já no contexto do interior do Estado de São Paulo, o cenário na grande maioria dos municípios, caracteriza-se por escassez ou ausência de aparelhos culturais, e essa lacuna é em parte suprida pela atuação de grupos chamados de amadores (assim denominados por não se sustentarem economicamente deste trabalho), cujas atividades constituem, muitas vezes, a única opção de teatro em suas cidades.

Como ponto de partida para a pesquisa foi realizada uma busca por grupos de teatro com sede em municípios do interior de São Paulo. Os grupos foram convidados a participar de uma entrevista semiestruturada, que poderia acontecer via aplicativos de comunicação digital, e-mail ou pessoalmente.

Os tópicos abordados foram: característica do grupo, espaço-sede, atividades realizadas, relação com o público, sustentabilidade econômica, relação e percepção acerca das políticas públicas e leis de incentivo e resiliência. Dos 32 grupos contatados, 15 aceitaram participar da pesquisa. 


\title{
Espaço-sede e a luta por território
}

O espaço transcende sua função de mero espaço físico, provocando uma aproximação com a comunidade e possibilitando uma construção de identidade a partir dos encontros proporcionados por ele. Cleiton Pereira, integrante do Grupo de teatro Contadores de Mentira ${ }^{3}$, em entrevista (2018), destaca essa importância dos espaços-sede para o desenvolvimento da cultura nos territórios:

\begin{abstract}
Não é um Espaço apenas de atrações - embora também cumpra esta função - mas, sobretudo, um encontro de luta, de potência, de força, e acúmulo de energia. É também para criar demarcações e ocupação no próprio território em que vivemos. É para ocupar cantos da cidade e da região do Alto Tietê. É para fortalecer os grupos locais. Mantemos o Teatro Contadores de Mentira mesmo sem recursos, contando com a generosidade e o apoio de outros fazedores porque acreditamos na sua força. Queremos contribuir para o giro dos grupos. Queremos contribuir para que haja circulação para além das capitais. Queremos manter esse espaço porque ele possibilita o encontro, e, porque em nós, é o grande sentido de fazer o que fazemos há tantos anos. O encontro é o que nos faz saltar.

(Cleiton Pereira, Grupo Contadores de Mentira, 2018)
\end{abstract}

Para atenuar a ausência de espaço-sede, alguns grupos buscam parceria com órgãos públicos, escolas de artes e artistas, ou utilizam as residências dos integrantes.

O alto custo financeiro e dificuldades para geração de renda para cobrir as despesas de um espaço foi o viés com maior apontamento e fator impeditivo para concretização de um espaço-sede. Fator esse apresentado como indicador determinante apontado por Robert de Arruda Coelho do grupo Quadrilha de Teatro Notívagos Burlescos (2019) na desativação de sua sede:

Durante o último ano de atividade o grupo buscou caminhos para manter as atividades e o espaço através das contribuições mensais, campanhas de arrecadação e bilheterias e cachês de apresentações. Infelizmente a quantidade de dinheiro arrecadado não era suficiente para pagar todas despesas e o grupo decidiu fechar o espaço.

\footnotetext{
${ }^{3} \mathrm{O}$ grupo Contadores de Mentira tem sede no município de Suzano/SP e foi fundado no ano de 1995.
} 
(Robert de Arruda Coelho, Quadrilha de Teatro Notívagos Burlescos, 2019)

Cleiton do grupo Contadores de Mentira, relatou também na entrevista que os grupos de teatro do interior vivem uma constante ameaça de perder os seus espaços.

Um exemplo significativo desse problema e que ganhou grande visibilidade na mídia é a atual tentativa pelo grupo empresarial de Sílvio Santos de reverter o tombamento da sede do Teatro Oficina ${ }^{4}$, frequentado por inúmeros espectadores, não apenas do Brasil, mas também de outros países. É desastroso concluir que o peso histórico e o valor cultural construídos em um território sejam colocados à venda sem pensar no quanto isso prejudica a identidade construída através das expressões artísticas. Esse caso ilustra os descabidos embates enfrentados por artistas em relação à manutenção dos seus espaços culturais. É um estar em alerta constante, é preciso cotidianamente defender os espaços e lutar pelo seu reconhecimento e continuidade.

\section{Sustentabilidade econômica - entre os retrocessos e os desafios da produção cultural}

Um dos pontos estruturantes dessa pesquisa e que esteve presente em todas as entrevistas realizadas foram as estratégias de financiamento utilizadas pelos grupos. É evidente a inviabilidade de contar apenas com a bilheteria como forma de subsídio, uma vez que esse tipo de arrecadação não consegue suprir, por exemplo, os gastos de manutenção de um espaço-sede, tampouco os meses de trabalho que antecedem à temporada aberta ao público.

\footnotetext{
${ }^{4}$ A Companhia de Teatro Oficina Uzyna Uzona foi fundada em 1958 e tem sua sede no município de São Paulo/SP. O Oficina como é popularmente conhecido, ganhou maior destaque em 1967 com "O Rei da Vela", de Oswald de Andrade, espetáculo integrante do movimento tropicalista. A partir deste momento a companhia investe na antropofagia como linguagem na criação de seus espetáculos. Constitui-se como figura importante um de seus fundadores, o diretor artístico José Celso Martinez Correia. O Teatro Oficina é referência na cena nacional e palco de resistência e luta nas esferas políticas e sociais.
} 
Dentre as atividades voltadas à geração de renda relatadas pelos grupos entrevistados, foi destacada a montagem e apresentações de espetáculos teatrais, seguida respectivamente por produção de eventos, oficinas e intervenções.

Os grupos relataram não buscar parcerias com empresas privadas por falta de motivação ou por tentativas anteriores desse tipo de parceria sem êxito. Entre os grupos que buscam parcerias com a iniciativa privada, a maioria busca apoio para custeamento dos trabalhos. Porém, relatam que o retorno mais comum se dá através de permutas. Essas permutas, na maior parte dos acordos, cobrem apenas uma pequena parcela dos custos totais do projeto em pauta.

Quanto à participação dos grupos em leis de incentivo e políticas públicas voltadas ao teatro, auferiu-se que apenas uma pequena parte dos pesquisados não utilizaram ou não foram contemplados por essas ações afirmativas. Dessas, o PROAC (Programa de Ação Cultural do Estado de São Paulo) foi o programa com o maior número de participações.

Esse bloco da entrevista retoma o debate que permeia os percalços dos grupos de teatro para viabilizar estratégias que sejam satisfatórias no tocante à geração de renda.

Nas eleições de 2018, os governantes eleitos apresentaram como plano de governo minimizar ainda mais os incentivos a produções culturais tanto no âmbito nacional como estadual. Construindo um cenário político que demoniza a arte e sucateia as políticas públicas e leis de incentivo culturais. O mesmo Estado, na figura de seus representantes, que incita a população e dita regras sobre que tipo de arte deve ser consumida ou não e propaga ações que desvalorizam a arte e a cultura é o que lança campanha para que esse setor trace caminhos de financiamento junto ao mercado, por compreender que o setor público não tem a obrigação de subsidiar essa área.

Ações ligadas à formação de público - que teriam como objetivo aproximar a população de linguagens artísticas menos difundidas pelos meios de comunicação em massa - acabam recaindo única e exclusivamente na responsabilidade dos artistas. Esse tipo de ação, com caráter educativo, pede continuidade e tem resultados a longo prazo. Sem o engajamento 
governamental, as iniciativas nesse campo aparecem como ilhas isoladas alcançando apenas uma pequena gama de pessoas em cada ação e dificilmente tem continuidade. Ampliando a distância entre algumas expressões artísticas e o público.

Um caminho que se firma como alternativa de fortalecimento é a organização de grupos de teatro e agentes culturais em redes como meio de ampliar as ações e conseguir chegar em locais onde há menor acessibilidade. Como estratégia de sobrevivência formam-se associações, cooperativas e ajuntamentos de artistas que se unem tanto para lutar na instância política como para partilhar espaços, trocar vivências e dividir o custo de espaços e trabalhos.

As lutas pela ampliação e conservação de políticas públicas e leis de incentivo para a arte e cultura continuam e continuarão a existir. Percebe-se, na colocação de alguns dos grupos pesquisados, a valia de tais medidas para suas vidas, pois conforme demonstrado no início desse tópico, a viabilização do fazer teatral de muitos espetáculos e ações só foi possível através de prêmios conquistados em editais, com destaque para o PROAC que, embora esteja longe de suprir as demandas, é um incentivador para as criações e desenvolvimento de grupos de teatro.

Em resposta a qual é o pensamento do grupo em relação às leis de incentivo e políticas públicas voltadas ao teatro, os entrevistados expuseram:

As políticas culturais são fundamentais. Está previsto na constituição e chancelado pela UNESCO que a Cultura é um direito de todos e que é preciso garantir o acesso aos meios de produção e fruição. É preciso fortalecer cada vez mais essas políticas e produzir conteúdo relacionado às melhorias que esse incentivo causa na sociedade, como o desenvolvimento afetivo, intelectual e emocional das pessoas, bem como o desenvolvimento econômico, sendo a economia criativa uma das frentes que mais cresce no mundo todo. (Fernando Vasques e Mimi Tortorella, Cia Beira Serra de Teatro e $\mathrm{Circo}^{5}$, 2018)

Eu acho que é sempre importante, as leis elas ampliaram as possibilidades dos grupos se manterem, se organizarem, porque para ser aprovado você precisa estar organizado, então isso força uma organização do trabalho, do grupo e de pesquisa, mas, recentemente por conta dos valores que o governo estipula o

${ }^{5} \mathrm{~A}$ Cia Beira Serra de Circo e Teatro tem sede no município de Botucatu/SP e foi fundada no ano de 2014. 
estadual e o federal, e as prefeitura locais, os valores não dão conta de manter os grupos pelo baixo valor, e por isso motivo os grupos tem que buscar por outras estratégias. (José Antônio da Silva, Grupo Andaime de Teatro ${ }^{6}$,2018)

\section{Resiliência e os modos de existir}

O campo onde se encontram as discussões sociopolíticas, que englobam questões de cunho econômico e desigualdade social, podem ser entendidas como um ambiente propício ao desenvolvimento de resiliência. DELL'AGLIO, KOLLER, YUNES (2006) conceituam resiliencia como a capacidade de adaptar-se às diferentes formas de exploração e descaso que constituem um contexto em que se está inserido e, frente a um cenário desfavorável, criar mecanismos para seguir em frente. É por esse viés que o termo foi tratado nesta pesquisa.

Desde o início, quando me propus a escrever o presente estudo, quis entender o que motiva os grupos de teatro a se manterem resilientes. $O$ interesse primordial era o de entender não apenas os itens que desestimulam a existência de grupos de teatro no fazer teatral, mas, sobretudo, o que faz com que os grupos de teatro persistam e se mantenham ativos durante longo prazo. Barba (1991, p.34), defende que o teatro não pode mais viver a ilusão de retornar aos tempos de glória como na Grécia antiga e sim atentar-se por batalhar e dedicar-se ao treinamento e organização do processo criativo como forma de sobrevivência. Ele coloca que esse ofício proporciona uma mudança no campo individual e isso, por consequência, traz transformações na sociedade. Essa convicção é reafirmada quando expressa que "É preciso perguntar-se: $O$ que significa o teatro para mim? A resposta transformada em ação, sem compromissos nem precauções, será a revolução no teatro" (Barba, 1991, pág. 34).

Em movimento semelhante, alguns grupos pesquisados apresentaram em seus relatos elementos que se aproximam dessa premissa como impulso na criação de suas pesquisas para o fazer teatral:

\footnotetext{
${ }^{6} \mathrm{O}$ grupo Andaime Teatro tem sede no município de Piracicaba/SP e foi fundado no ano de 1986.
} 
A primeira, o que motiva nossa produção principalmente é tentar olhar, entender, discutir e criar a partir das relações contemporâneas, a partir do modo que nós nos colocamos hoje no mundo, tentar de certa forma colocar esse modo de ver no mundo de criar e fazer as coisas em debate, questões fundamentais que atravessaram todo a existência do homem também estão no nosso trabalho, por exemplo questões ligadas a filosofia de quem nós somos, criar maneiras de viver, de estar no mundo, isso é algo que nos motiva, e o principal é criar a partir da nossa existência, entender a partir da nossa existência qual é a função desse fazer, desse teatro, o que nós contribuímos para a formação dessa sociedade, desse momento político que nós vivemos, uma síntese seria criar novas formas de existências. (André Ravasco, Cia Do Trailler - Teatro em Movimento ${ }^{7}$, 2019)

Chamamos nosso teatro de "celebração". Em algum momento na construção de nosso grupo percebemos nas manifestações populares, nas rezadeiras, nas celebrações religiosas, nas manifestações populares, nos terreiros, nas danças orientais um fenômeno que nos tocava e nos perguntávamos por que aquilo nos envolvia. Era o resultado de uma série de perguntas que ainda fazemos para justificar algumas de nossas escolhas.

Em alguns anos percebemos uma dramaturgia em nosso corpo, às vezes estranho à formação tradicional de atores, mas com capacidade criativa inerente. Percebemos que era possível celebrar - tema e não apenas interpretá-lo na dramaturgia da razão. Optamos ao longo do tempo por celebrar a relação entre plateia, artistas, obra, instante. Percebemos que é possível contar uma história pela lembrança, pela imagem, pelo cheiro, pela dança, pela comida, pela cachaça, pela sombra, pela escuridão, pela luz, pelo silêncio. Percebemos também que o público não precisa ser apenas observador, que é generoso ao nos dedicar algumas poucas horas para o efêmero, para o encontro.

Encontramos nas tradições também a ideia de que nosso ofício é próximo ao do artesão. Somos artesãos teatrais. Assim, como o alfaiate, como o chapeleiro, que trabalham incansavelmente para produzir um belo chapéu, uma calça. Celebração, antropologia, observação, simbolismos, efêmeros, brincantes, potências, corpos, quedas são eixos de nosso teatro. (Cleiton Pereira, Grupo Contadores de Mentira, 2018)

\section{A resiliência dos grupos em permanecer existindo e trabalhando} ativamente não esmorece frente aos desafios. Os problemas encontrados tornam-se material para criação e energia para a luta. Nesta parte que finaliza a pesquisa procurou-se investigar o que os grupos almejam como retorno. Estes são alguns relatos:

A nossa extrema paixão pela arte teatral e pela formação de um público para teatro. O retorno pode ser resumido na felicitação de poder levar cultura para lugares que jamais tiveram a possibilidade

\footnotetext{
${ }^{7}$ A Cia do Trailler - Teatro em Movimento tem sede no município de São José dos Campos/SP e possui 17 anos de existência.
} 
deste encontro. (Gilson Camara, Cia de Artes Cênica Gil Vicente ${ }^{8}$, 2018)

Teatro é a nossa profissão, a nossa missão e a nossa maneira de se relacionar com a realidade que nos cerca. Através dele buscamos despertar olhares e provocar reflexões que tornem essa realidade um lugar melhor para se viver. Acreditamos que seja possível sermos remunerados pelo nosso trabalho para vivermos com dignidade. Estamos na luta em busca de caminhos para que isso aconteça. (Robert de Arruda Coelho, Quadrilha de Teatro Notívagos Burlescos, 2019)

Nosso grupo trabalha com temas que estão presentes na realidade da cidade e região onde mantemos nossa sede. Esperamos como retorno, que reflexões e mudanças possam acontecer a partir das atividades que propomos e dos espetáculos que criamos. (Fabia Pierangeli de Lima, Grupo Teatro Girandolá9 , 2018)

Nossa sociedade tende a caracterizar o fazer artístico como algo não produtivo por pensar que o teatro e outras artes são somente uma forma de entretenimento, tanto para quem assiste quanto para quem a desempenha, desconsiderando todo o percurso transcorrido pelo artista para fazer com que o espectador seja afetado pelo trabalho desenvolvido. Possani (2017, p.76), em sua tese, descreve o caminho e o treinamento que o Grupo Matula ${ }^{10}$ exigia de si como preparação e método para as suas criações:

Nesse período inicial do Matula os quatro primeiros anos, de 2000 a 2004, mais ou menos éramos bastante rigorosos com relação a esse espaço que chamávamos de treinamento. Eram pelo menos três encontros de quatro horas por semana, sem atraso, sem cancelamento. Se porventura o local pedia uma limpeza era preciso chegar meia hora antes de maneira a preservar as quatro horas integrais de trabalho. Lembro-me de um feriado em que não tínhamos sala (pois usávamos espaços da Unicamp na ocasião) e ficamos procurando lugares alternativos para trabalhar. Diante da falta de opções, resolvemos fazer nosso encontro no quintal da casa de uma das atrizes que tinha um gramado de tamanho suficiente. Como o local era aberto, começamos o trabalho às seis da manhã para terminar por volta das $10 \mathrm{~h}$ quando o sol ainda estaria aceitável. Isso significou acordar às quatro e pouco, para tomar café e chegar a tempo, de ônibus, meio de transporte de quase todos na época. Em nenhum momento passou pela nossa

${ }^{8} \mathrm{~A}$ Cia de Artes Cênicas Gil Vicente foi fundada no ano de 1997 na cidade de Paraguaçu Paulista/SP, depois em 1998 teve como sede de seus trabalhos a cidade de Rio Claro/SP, no final do referido ano transfere-se para o município de Avaré/SP, sede atual do grupo.

${ }^{9} \mathrm{O}$ grupo Teatro Girandolá tem sede no município de Francisco Morato/SP e foi fundado no ano de 2007.

${ }^{10} \mathrm{O}$ Grupo Matula Teatro tem sede no município de Campinas/SP e foi fundado no ano de 2000. 
cabeça que poderíamos simplesmente não treinar naquele dia. (Possani, 2017, p.76)

Pode-se entender que o estímulo para os grupos continuarem com seus trabalhos é a crença e o sentimento que vão além do retorno financeiro, sem descartar o merecimento da luta por financiamentos. É um compromisso com a transformação da sociedade, cujo comportamento é temática nos palcos.

No contexto do conceito de resiliência conforme tomado para este estudo, os grupos pesquisados podem ser compreendidos como resilientes, visto que, em totalidade, eles firmam-se no fazer teatral e permanecem vivos e ativos, transpondo as dificuldades encontradas e suas diferentes nuances em virtude do que os move.

\section{Considerações finais}

A criação tem origem nas muitas vozes, ideias, lutas e identidades que no palco se estendem através de estética e linguagem expressas no corpo dos atuantes para serem compartilhadas. Entretanto, embora os grupos encontrem dentro de si força para lutar procurando subsistir, não deve-se entender que essa condição é poética e que nutre a alma do artista. Dar condições para que a arte e a cultura se desenvolvam é vital para democratizar o acesso a elas, culminando na descentralização desse acesso. Encontrou-se, a partir dos dados apresentados por este estudo, que o caráter financeiro se exprime como ponto que mais afeta e desmotiva a existência dos grupos teatrais.

Quanto a manterem-se resilientes, foi revelado que o desejo de transformar as relações sociais, e de ser ferramenta de luta para alcançar uma sociedade mais humana que se perceba e perceba a arte como bem necessário por se tratar de lugar de diálogo aberto e de expressão que se materializa em consequência de um trabalho de treinamento e pesquisa, é o que os fortalece frente aos desafios. 
Embora, em unanimidade, os grupos tenham destacado como fatores motivacionais para resiliência o desejo de provocar mudanças sociais, políticas e ambientais nas relações humanas, é importante reforçar que ainda assim o aporte financeiro é decisivo para sustentar um grupo em atividade. Nota-se, através dos depoimentos colhidos, que grupos mais novos tendem a sofrer mais em termos de condições de estrutura, por se tratar de grupos, em sua maioria, sem espaço-sede e com menor índice de aprovação em editais.

A carência de estruturas e políticas públicas que incentivem o surgimento e existência de grupos de teatro gera consequência direta nas dificuldades em sustentar-se financeiramente e manter um espaço-sede. Relacionado a isso, outros problemas são percebidos, tais como conseguir tempo de dedicação aos trabalhos do grupo e disponibilidade para organização sobre as questões da produção e gestão cultural, em busca de traçar planejamentos referentes aos objetivos do grupo. Essas são questões pertinentes e que necessitam de um debate consistente, do incentivo de novas pesquisas e, sobretudo, da construção de políticas culturais estruturantes, que possibilitem condições para a sobrevivência e continuidade de expressões artísticas e culturais que operam de maneira diferente do que seria um mercado cultural pautado somente em premissas financeiras e capitalistas.

Essa políticas são fundamentais para o fomento e salvaguarda de coletivos e espaços que realizam um trabalho contínuo e que, muitas vezes, são responsáveis por ações de formação e de acesso a manifestações culturais em um território, contribuindo para uma perspectiva de direito cultural ampla e democrática.

\section{Referências Bibliográficas}

SILVA, José Antônio da. ANDAIME TEATRO. Entrevista concedida à Giovanna Pereira de Souza, gravação, em 20.12.2018

BARBA, Eugênio. Além das ilhas flutuantes. Tradução de Luís Otávio Burnier. Ed. Unicamp, 1991, p. 32-34 
CARREIRA, André. Teatro de Grupo: modelo de organização e geração de poéticas. Rev. Teatro Transcende, Blumenau, n. 11, p. 95-98, ano.2005. Disponível em <http://files.discutindoaeticanoteatro.webnode.com/200000061-

3758138524/TEATRO\%20DE\%20GRUPO.pdf >. Acesso em 05 set. 2018. VASQUES, Fernando; TORTORELLA, Mimi. CIA BEIRA SERRA DE CIRCO E TEATRO. Entrevista concedida à Giovanna Pereira de Souza, por email, em 17.12.2018

CAMARA, Gilson. CIA DE ARTES CÊNICAS GIL VICENTE. Entrevista concedida à Giovanna Pereira de Souza, por email, em 12.12.2018 RAVASCO, André. CIA DO TRAILLER - TEATRO EM MOVIMENTO. Entrevista concedida à Giovanna Pereira de Souza, gravação, em 14.01.2019 PEREIRA, CLEITON. CONTADORES DE MENTIRA. Entrevista concedida à Giovanna Pereira de Souza, por email, em 19.12.2018 COSTA, Iná Camargo. Teatro de grupo contra o deserto de mercado. Rev. Artcultura, v. 09, n. 15, p. 17-29, jul.-dez. 2007. Disponível em < http://www.artcultura.inhis.ufu.br/PDF15/H\&T_Costa.pdf>. Acesso em 20 dez. 2018. DELL'AGLIO, Debora Dalbosco; KOLLER, Sílvia H; YUNES, Maria Angela Mattar. Resiliência e psicologia positiva: Interfaces do risco a proteção. Ed. Casa do psicólogo, 2006, p. 13 POSSANI, Maria Alice. O ator em jogo: tessituras entre corpo, cena e cidade. 2017. 226 f. Tese (Doutorado em Artes da Cena) - Universidade Estadual de Campinas. Campinas. Disponível em $<$ http://repositorio.unicamp.br/jspui/bitstream/REPOSIP/332040/1/Possani_MariaAli ce_D.pdf>. Acesso em 25 mar. 2019 COELHO, Robert de Arruda. QUADRILHA DE TEATRO NOTíVAGOS BURLESCOS. Entrevista concedida à Giovanna Pereira de Souza, por email, em 11.01.2019

LIMA, Fabia Pierangeli. TEATRO GIRANDOLÁ. Entrevista concedida à Giovanna Pereira de Souza, por email, em 14.12.2018

VIANNA, Tiche. Teatro de Grupo: um espaço de aliança a favor da arte. Rev. Subtexto, n. 04, p. 56-57, ano.2007. Disponível em < http://galpaocinehorto.com.br/wp-content/uploads/subtexto4.pdf>. Acesso em 20 jan. 2019. 


\section{Grupos participantes}

\section{TEATRO CONTADORES DE MENTIRA}

Página facebook: https://www.facebook.com/TeatroContadores/

\section{CIA FANTOCCINI}

Página facebook: https://www.facebook.com/ciafantoccini/

Site: https://ciafantoccini.wixsite.com/ciafantoccini

\section{TEATRO GIRANDOLÁ}

Site: www.conpoema.org

\section{CIA BEIRA SERRA DE CIRCO E TEATRO}

Site: www.ciabeiraserra.com

Facebook: www.facebook.com/ciabeiraserra

CIA DO TRAILLER - TEATRO EM MOVIMENTO

Facebook: https://www.facebook.com/Cia-Do-Trailler-Teatro-Em-Movimento365170853839855/

EIXO 6 TEATRAL

Facebook: https://www.facebook.com/eixo6/?ref=bookmarks

ANDAIME TEATRO

Facebook: https://www.facebook.com/andaimeteatro/

\section{GRUPO AWEN}

Facebook: https://www.facebook.com/GrupoAwenSantos/

\section{GRUPO MATULA TEATRO}

Site: www.grupomatulateatro.com

Facebook: https://www.facebook.com/GrupoMatulaTeatro/

\section{GRUPO TOMALÁDÁCÁ DE TEATRO}

Facebook: https://www.facebook.com/tomaladacadeteatro 
Resiliência e sustentabilidade: desafios do fazer teatral de grupos de teatro do interior de São Paulo

NARRAÇÃO ORAL TRADICIONAL - VIVA HISTÓRIA VIVA

Facebook: https://www.facebook.com/narracaooraltradicionalportofeliz2017/

QUADRILHA DE TEATRO NOTÍVAGOS BURLESCOS

Facebook: https://www.facebook.com/notivagosburlescos/

VARANDA PRODUÇÕES TEATRAIS

Facebook: https://www.facebook.com/varandateatro/

CIA DE ARTES CÊNICA GIL VICENTE

Facebook: https://www.facebook.com/ciagilvicenteavare/

GRUPO FÂNTASO

Facebook: https://www.facebook.com/grupofantaso/

Site: http://fantasoproducoes. wixsite.com/fantaso 